\title{
Ataxia, hypoplastic vermis and keyhole connection sign: is it the variant form of Dandy-Walker complex?
}

\author{
Osama S M Amin
}

Department of Neurology، Sulaimaniya General Teaching Hospital, Sulaimaniya City, Iraq

\section{Correspondence to} Dr Osama S M Amin, dr. osama.amin@gmail.com
To cite: Amin OSM. BM Case Reports Published online: 12 December 2012 doi:10.1136/bcr-2012 007152

\section{DESCRIPTION}

A 12-year-old girl has a progressive instability of stance and gait since the age of 2 years. She demonstrates mild mental subnormality and signs of cerebellar incoordination. A diagnosis of an ataxic form of cerebral palsy was made at the age of 3 years. When she was 9 years old, she started to develop occasional vomiting and headache which were ascribed to 'hydrocephalus'. Accordingly, shunting surgery was performed (figure 1). Both headaches and vomiting remarkably improved; however, the cerebellar dysfunction remained. Her up-to-date brain MRI is shown (figure 2).

The symptomatology and brain imaging do not categorise the girl as having Dandy-Walker malformation or Dandy-Walker mega cisterna magna; she fits the 'variant form' of Dandy-Walker complex. ${ }^{1}$ This form is very heterogeneous and results in a multitude of phenotypes. ${ }^{2}$ The brainstem per se and the lateral ventricles are normal and the posterior fossa is normal or typical mildly enlarged. The midline vermis is hypoplastic and the cisterna magna communicates, through an enlarged vallecula, with the posterior/inferior aspect of the fourth ventricle forming the so-called keyhole connection sign. Therefore, posterior fossa cystic spaces appear to be enlarged.

Supratentorial malformations are uncommon and hydrocephalus is found in $25 \%$ of patients only. The typical 'torcular-lambdoid inversion sign' of Dandy-Walker malformation is not encountered in the variant form.

Patients with less severe symptoms and mild anomalies usually hold a good prognosis. The presence of severe malformations (including multiple intracranial and extracranial anomalies) portends a gloomy outlook.

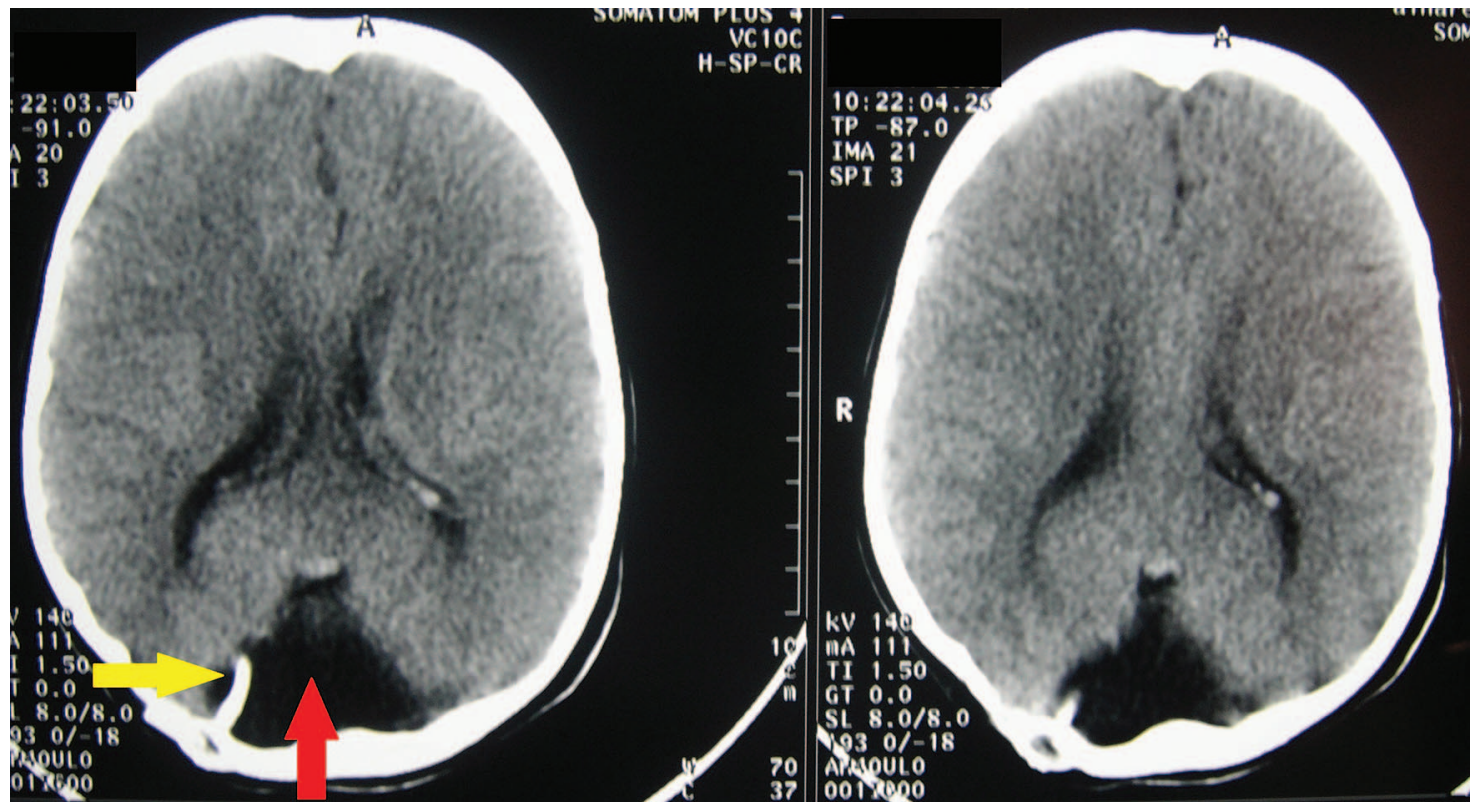

Figure 1 Axial non-contrast CT brain scan of the patient, which was done 3 years ago. Note the site of the shunt (yellow arrow), which was placed into the posterior fossa's cisterna magna (red arrow). The patient developed a few bouts of headache and vomiting at that time and her paediatrician referred her to a neurosurgeon, who suggested that hydrocephalus is the cause of these complaints and he did this shunt. We think that the paediatrician and the neurosurgeon had missed the diagnosis of Dandy-Walker complex-variant form in this patient and the dilated cisterna magna prompted them to think of hydrocephalus. 


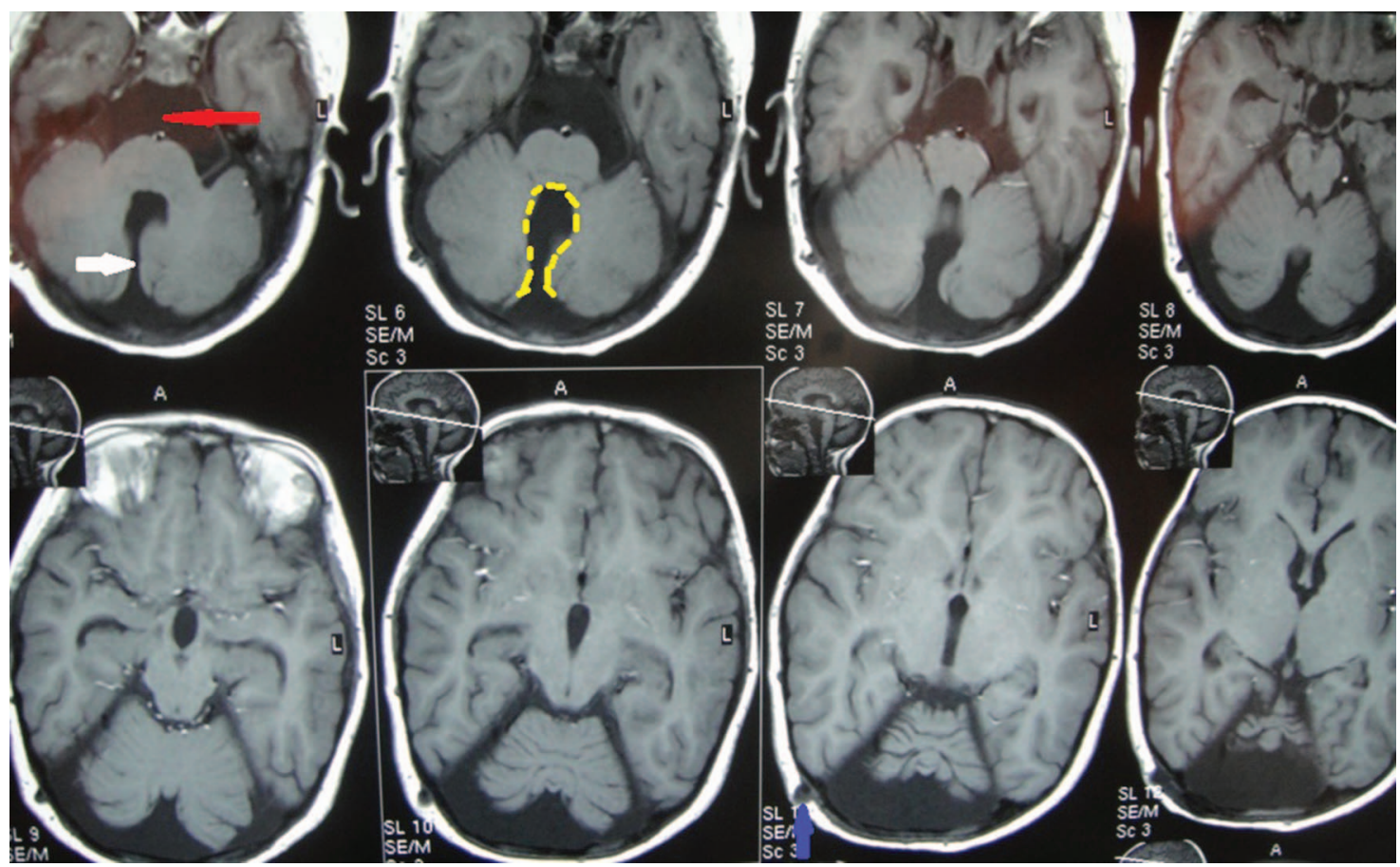

Figure 2 Axial T1-weighted brain MRI film at the level of the posterior fossa. Note the mildly enlarged posterior fossa, absence of the lower midline cerebellar vermis (white arrow), keyhole connection sign between the 4th ventricle and cisterna magna (marked by yellow dots) and the enlarged pre-pontine cistern (red arrow). The bony defect in the right occipital bone represents the site of the shunt (blue arrow). The brainstem per se looks normal. The patient has a variant form of Dandy-Walker complex. In general, her cerebellar signs and mild mental subnormality have not changed since early childhood; her gait and stance instability had been somewhat stable during the past few years.

\section{Learning points}

- Dandy-Walker complex-variant form defines patients who do not fit the fully-fledged Dandy-Walker malformation or Dandy-Walker mega cisterna magna categories and represents a less severe form of this ciliopathy with a relatively good prognosis.

- Characteristically, torcular-lambdoid inversion sign of Dandy-Walker malformation is not encountered in the variant form. The posterior fossa may be mildly enlarged and this, together with enlarged posterior fossa cystic spaces, may prompt the neurologist to think of hydrocephalus and unnecessary shunting surgery may ensue.

- Coexistent intracranial and extracranial anomalies are uncommon but their presence portends a poor prognosis.
Competing interests None.

Patient consent Obtained.

Provenance and peer review Not commissioned; externally peer reviewed.

\section{REFERENCES}

1 Sasaki-Adams D, Elbabaa SK, Jewells V, et al. The Dandy-Walker variant: a case series of 24 pediatric patients and evaluation of associated anomalies, incidence of hydrocephalus, and developmental outcomes. J Neurosurg Pediatrics 2008;2:194-9.

2 Murray JC, Johnson JA, Bird TD. Dandy-Walker malformation: etiologic heterogeneity and empiric recurrence risks. Clin Genet 1985;28:272-83.

3 Barkovich AJ, Kjos BO, Norman D, et al. Revised classification of posterior fossa cysts and cystlike malformations based on the results of multiplanar MR imaging. AJR Am J Roentgenol 1989;153:1289-300.

Copyright 2012 BMJ Publishing Group. All rights reserved. For permission to reuse any of this content visit

http://group.bmj.com/group/rights-licensing/permissions.

BMJ Case Report Fellows may re-use this article for personal use and teaching without any further permission.

Become a Fellow of BMJ Case Reports today and you can:

- Submit as many cases as you like

- Enjoy fast sympathetic peer review and rapid publication of accepted articles

- Access all the published articles

- Re-use any of the published material for personal use and teaching without further permission

For information on Institutional Fellowships contact consortiasales@bmjgroup.com

Visit casereports.bmj.com for more articles like this and to become a Fellow 